\title{
Nanogoethite is the dominant reactive oxyhydroxide phase in lake and marine sediments
}

\author{
Claar van der Zee* \\ Darryl R. Roberts \\ Denis G. Rancourt* \\ Department of Physics, University of Ottawa, Ottawa, Ontario K1N 5N6, Canada \\ Caroline P. Slomp \\ Department of Geochemistry, Faculty of Earth Sciences, Utrecht University, Budapestlaan 4, 3584 CD Utrecht, Netherlands
}

\begin{abstract}
Iron oxides affect many elemental cycles in aquatic sediments via numerous redox reactions and their large sorption capacities for phosphate and trace elements. The reactive ferric oxides and oxyhydroxides are usually quantified by operationally defined selective chemical extractions that are not mineral specific. We have used cryogenic ${ }^{57} \mathrm{Fe}$ Mössbauer spectroscopy to show that the reactive iron oxyhydroxide phase in a large variety of lacustrine and marine environments is nanophase goethite $(\alpha-\mathrm{FeOOH})$, rather than the assumed surface-complex-stabilized, two-line ferrihydrite and accompanying mixture of clay and oxyhydroxide Fe-bearing phases. This result implies that the kinetic and stability parameters of the type of nanogoethite that we observe to be present in sediments should be first determined and then used in models of early diagenesis. The identity and characteristics of the reactive phase will also set constraints on the mechanisms of its authigenesis.
\end{abstract}

Keywords: iron oxides, goethite, Mössbauer spectroscopy, early diagenesis, sediments.

\section{INTRODUCTION}

Iron minerals in marine and lacustrine sediments influence the cycling of $\mathrm{C}$ and $\mathrm{S}$ and largely control the fates of key nutrients such as $\mathrm{P}$ and of toxic heavy metals such as As (Berner, 1973; Belzile and Tessier, 1990; Lovley and Phillips, 1988; Raiswell and Canfield, 1998). Reactive iron oxides and oxyhydroxides are reductively dissolved in anaerobic sediments, releasing $\mathrm{Fe}^{2+}{ }_{(\mathrm{aq})}$, which precipitates as authigenic iron oxides and oxyhydroxides, following the upward diffusion of $\mathrm{Fe}^{2+}{ }_{\text {(aq) }}$ and its reoxidation (Froelich et al., 1979). Iron oxides in aquatic sediments are thought to constitute a continuum from amorphous to crystalline structures; however, the main diagenetic oxidation product is thought to be ferrihydrite [Fh, often termed hydrous ferric oxide, $\mathrm{HFO}$, nominally $\mathrm{Fe}(\mathrm{OH})_{3}$ or $\left.\mathrm{FeOOH}\right]$ (Thamdrup, 2000). With few exceptions, e.g., Drodt et al. (1997), who identified goethite and small amounts of hematite in a deep-sea sediment core by Mössbauer spectroscopy, the reactive iron oxides and oxyhydroxides have been quantified by operationally defined selective chemical extractions. Attempts at direct detection, identification, and quantification, using physical measurement methods

\footnotetext{
*Rancourt-Corresponding author. Present address: van der Zee-Laboratory of Chemical Oceanography and Water Geochemistry, Université Libre de Bruxelles, Campus de la Plaine, CP 208, Boulevard du Triomphe, B-1050 Brussels, Belgium.
}

such as X-ray diffraction (XRD) and transmission electron microscopy, have been frustrated by the nanocomposite nature of the minority-phase precipitate in aquatic sediments. We have used cryogenic ${ }^{57} \mathrm{Fe}$ Mössbauer spectroscopy (MBS) to identify the reactive diagenetic iron oxyhydroxide phase in a large variety of lacustrine and marine environments.

Cryogenic MBS is well suited to identify the reactive iron oxyhydroxide phase because (1) MBS is resonantly sensitive only to Fe, without any matrix artifacts, (2) it can resolve and separately quantify all the known iron oxides and oxyhydroxides (e.g., hematite, magnetite, maghemite, goethite, ferrihydrite), (3) it can distinguish the oxides from the Fe-bearing silicate, sulfide, and phosphate phases and from surface-complexed $\mathrm{Fe}^{2+}$ and organic matter-complexed $\mathrm{Fe}$, and (4) it deals equally well with nanophase and amorphous materials and with bulk crystalline materials. The hyperfine field is the effective local magnetic field experienced by the ${ }^{57} \mathrm{Fe}$ probe nucleus that causes a Zeeman splitting into a sextet. The iron oxides and oxyhydroxides are resolved through parameters that describe this sextet. The important problem of the superparamagnetism of iron oxide nanoparticles, which causes loss of hyperfine field splitting and of resolution in room-temperature (RT, 22 ${ }^{\circ} \mathrm{C}$ ) spectra, is solved in that all iron oxides and oxyhydroxides are hyperfine split at liquid helium temperature (LHT, $4.2 \mathrm{~K}$ ). In addition, an RT collapse of the sextet demonstrates nanoscale size, and the temperature dependence of the hyperfine splitting and spectral line shape can be used to estimate particle size (Rancourt, 2001).

\section{MATERIALS AND METHODS}

Sediment samples were freeze-dried for the MBS measurements. Experiments on biogenically produced ferrihydrites show no conversion to nanogoethite upon freeze-drying (Thibault, 2002). Details on sediment collection and handling can be found in Slomp et al. (2002) for the Mediterranean core, in van der Zee et al. (2002) for the other marine sediment samples, and in Kliza and Telmer (2001) for the boreal lake sediments.

The Mössbauer spectra were analyzed with the extended Voigt-based fitting method of correlated multiple hyperfine parameter distributions (Lagarec and Rancourt, 1997) as implemented in the Recoil spectral analysis software. This method allows independent and correlated distributions of hyperfine fields, quadrupole shifts, quadrupole splittings, and center shifts, for both sextet and doublet contributions, with each distribution modeled by the smallest statistically acceptable number of summed independent Gaussian contributions. The broadening of sextet lines is thereby modeled as arising entirely from static hyperfine field distributions (HFDs), to extract practical, 
operationally defined, characteristic spectral parameters.

\section{RESULTS}

That the reactive citrate-dithionitebicarbonate (CDB)-extractable Fe (where CDB should extract all free oxides except magnetite) is nanophase goethite is most clearly illustrated by examining the results for a sediment core retrieved from the central part of the eastern Mediterranean Sea (depth of 3390 m; see Table DR $1^{1}$ for sample descriptions). The core consists of calcite-rich, organic matter-poor hemipelagic sediment overlying partially oxidized sapropel (S1). The $\mathrm{CDB}$-extractable $\mathrm{Fe}$ depth profile shows a gradual increase in concentration as one moves into the oxidized sapropel. The peak value coincides with the current active oxidation front (Slomp et al., 2002) and results from the diagenetic precipitation of iron oxyhydroxide. The RT and LHT Mössbauer spectra of the core section having the maximum CDB-extractable Fe are shown in Figure 1, along with the fitted subspectral contributions. At RT, the resolved contributions are (1) a ferric doublet, (2) a ferrous doublet, and (3) a broad ferric line. On going to LHT, the ratio of the total ferric and total ferrous contributions is the same, within error, as at RT; however, magnetic hyperfine splittings now occur. The broad ferric line has disappeared, as has much of the spectral area of the ferric doublet, because both now contribute to a new and well-defined magnetic hyperfine sextet (solid line comprising six absorption lines) that is attributed to goethite (Murad and Johnston, 1987; Friedl and Schwertmann, 1996).

Goethite is identified as the majority oxyhydroxide phase in all core sections exhibiting a sextet at LHT (see Table DR2 [see footnote 1] for reference materials). The sextet spectral shapes and the fact that superparamagnetism occurs at RT are consistent with nanogoethite particles in the $2-12 \mathrm{~nm}$ size range (see discussion of goethite particle size section). The percentage of the total area of the spectrum that is related to each spectral component is equal to the percentage of the total $\mathrm{Fe}$ that is present in that component, assuming equal Mössbauer recoilless fractions of all components. The fraction of $\mathrm{Fe}$ corresponding to the nanogoethite sextet closely follows the fraction of total Fe that is CDB extracted (Fig. 2), thereby establishing that the reactive authigenic phase in this Mediterranean sediment is nanogoethite.

${ }^{1}$ GSA Data Repository item 2003146, Tables DR1 (sample descriptions) and DR2 (hyperfine parameters for reference materials), is available online at www.geosociety.org/pubs/ft2003.htm, or on request from editing@geosociety.org or Documents Secretary, GSA, P.O. Box 9140, Boulder, CO 80301-9140, USA.

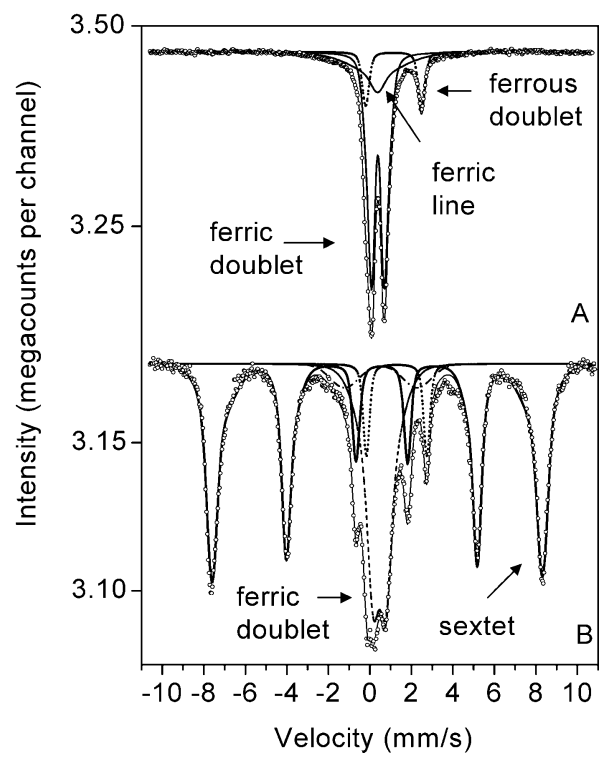

Figure 1. Mössbauer spectra (open circles) of Mediterranean sample with highest citrate dithionite-bicarbonate-extractable Fe content and model fits (main solid black line through data points is sum of individual components described in text). A: Roomtemperature (RT) spectrum composed of (1) ferric doublet from superparamagnetic oxyhydroxides and paramagnetic $\mathrm{Fe}^{3+}$-bearing minerals (dashed line), (2) ferrous doublet from paramagnetic $\mathrm{Fe}^{2+}$-bearing minerals (dotted line), and (3) broad ferric line (collapsed sextet) from superparamagnetic oxyhydroxide particles that have magnetic ordering temperatures near RT (solid subspectral line). B: Liquid helium temperature (LHT) spectrum composed of (1) ferric doublet from paramagnetic $\mathrm{Fe}^{3+}$-bearing minerals (dashed line), (2) ferrous doublet from paramagnetic $\mathrm{Fe}^{2+}$-bearing minerals (dotted line), (3) ferrous doublet from partially magnetically hyperfine split $\mathrm{Fe}^{2+}$ bearing minerals having magnetic ordering temperatures near LHT (dot-dash), and (4) sextet (solid line) arising from goethite.

A variety of additional marine sites was selected for cryogenic and RT MBS: one in the north Aegean Sea, one in the Mediterranean Sea (southwest of Rhodes), and four from contrasting depositional areas on the Iberian margin (northeast Atlantic Ocean). Samples were chosen from the depth intervals with the highest concentrations of citrate-ascorbatebicarbonate-extractable and CDB-extractable Fe (van der Zee et al., 2002). Lacustrine samples (core tops from each lake, which are oxic or include the oxic-anoxic boundaries, and some deeper core sections) from 7 boreal forest lakes (Canada) were selected from a large array of 99 lakes from a previous study (Kliza and Telmer, 2001), in order to span the full range of lake water $\mathrm{pH}(3.7-9.1)$ and organicmatter content (12\%-74\% dry weight). A core-top sediment from Lake Biwa, Japan, was also studied. We stress that in every sediment sample measured, chosen to contain a maximum amount of diagenetic oxyhydrox-

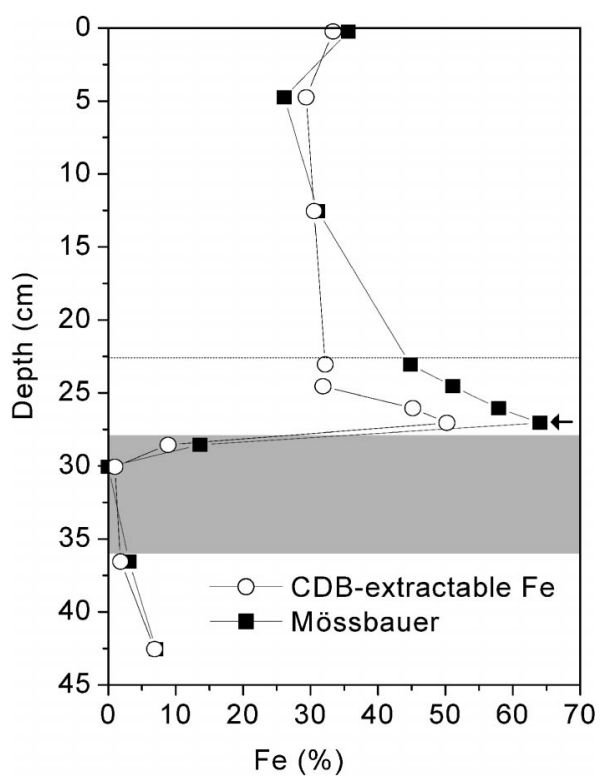

Figure 2. Depth profile of Fe in Mediterranean core. Open symbols-citrate-dithionitebicarbonate (CDB)-extractable Fe content as percentage of total Fe. Closed symbolspercentage of $\mathrm{Fe}$ in sextet as measured by cryogenic Mössbauer spectroscopy. Dotted line indicates top of original sapropel, and shaded area represents present-day sapropel layer. Area between dotted line and top of shaded area is that part of original sapropel that is oxidized. Arrow indicates sample for which room-temperature and liquid helium temperature Mössbauer spectra are given in Figure 1.

ide, a sextet was observed in LHT spectra that was unambiguously attributed to nanogoethite, as described in the next section.

\section{SPECTRAL IDENTIFICATION}

The sediment nanogoethite spectral contribution can be identified by its hyperfine field and quadrupole shift. Under static circumstances, a distribution of hyperfine fieldscharacterized by the average hyperfine field, $\langle H\rangle$, the most probable hyperfine field, $H_{\text {peak }}$, and the standard deviation, $\sigma_{\mathrm{HFD}}$, of the hyperfine field distribution (HFD) - arises from the distributions of local chemical and magnetic environments in the mineral. The quadrupole shift parameter, $\boldsymbol{\varepsilon}$, describes the effect of the local electric field gradient on the sextet pattern and has its own largely independent distribution characterized by the average $\langle\boldsymbol{\varepsilon}\rangle$. The small magnetocrystalline anisotropy constant of goethite and the small corresponding superparamagnetic fluctuation barriers of goethite nanoparticles cause homogeneous line broadening even at LHT (Murad and Johnston, 1987; Rancourt, 2001), unlike the situation with other nanophase oxyhydroxides. Homogeneous broadening, contrary to inhomogeneous or distribution broadening of spectral lines, is due to dynamic effects related to fluctuations in the local en- 

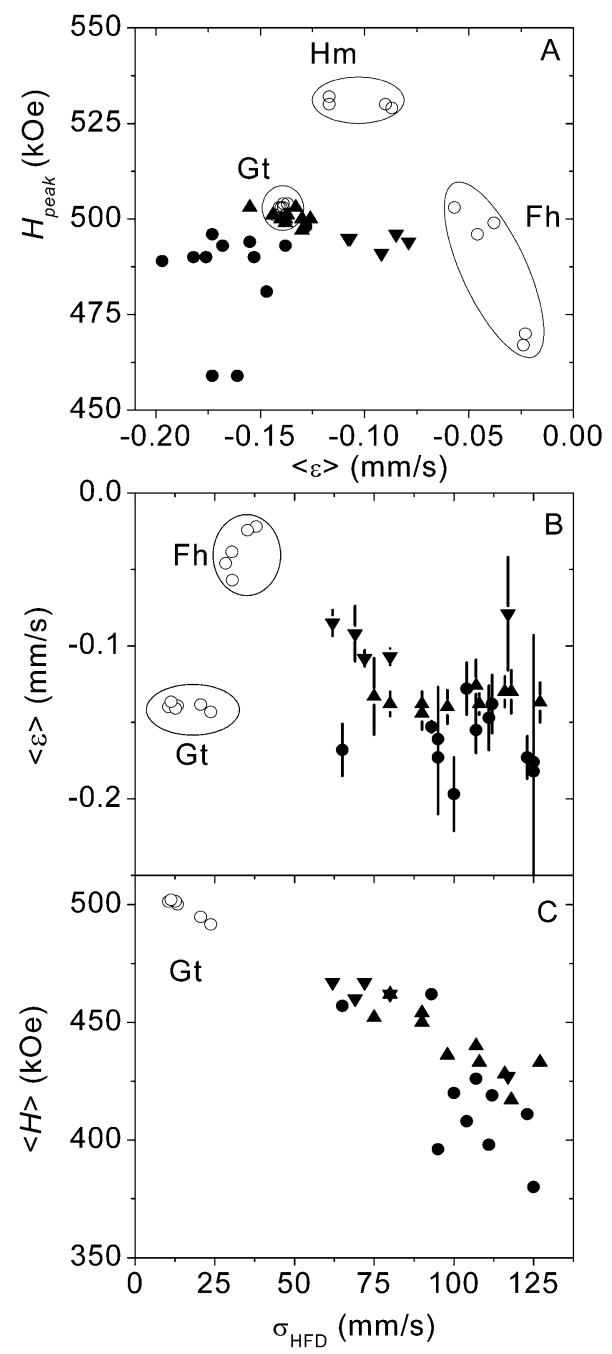

Figure 3. Key hyperfine parameters from liquid helium temperature sextets of sediment and reference oxides and oxyhydroxides. A: Most probable hyperfine field, $\boldsymbol{H}_{\text {peak }}$, plotted vs. average quadrupole shift, $\langle\varepsilon\rangle$, in natural samples (solid circles-lacustrine sediments; upward-pointing triangles-marine sediments; downward-pointing trianglesoxidized sapropel) and reference materials (empty circles) (Fh-ferrihydrites; Gtgoethites; Hm-hematites). B: $<\varepsilon>$ vs. standard deviation $\left(\sigma_{\mathrm{HFD}}\right)$ of hyperfine field distribution (HFD) for sediment samples and ferrihydrite and goethite reference materials. Error bars show two standard deviations; large values arise from those spectra with smaller and broader sextet contributions. C: Average hyperfine field, $\langle H\rangle$, vs. $\sigma_{\mathrm{HFD}}$, for sediment and reference goethite (empty circles) samples.

vironment of the probe nucleus, such as those arising from superparamagnetism. As a result, sediment nanogoethites exhibit a continuum of spectral shapes, extending to large line widths (modeled by the standard deviation, $\sigma_{\mathrm{HFD}}$, of the HFD) and to small average hyperfine fields $(<H>$ ), beyond those of any other oxyhydroxide material. This characteristic and other features of the spectral identification are illustrated in Figure 3, in which the marine, oxidized sapropel, lacustrine, and reference samples are compared. The reference samples shown include all those expected to be most relevant (Cornell and Schwertmann, 1996): synthetic microcrystalline hematites (20-150 nm) (Dang et al., 1998), synthetic nanohematite $(8 \mathrm{~nm})$, synthetic twoline ferrihydrites, synthetic six-line ferrihydrite, natural As-rich and $\mathrm{Si}$ - and $\mathrm{C}$-bearing ferrihydrites (Rancourt et al., 2001), and a suite of synthetic nanogoethites $(7-35 \mathrm{~nm})$. We conclude that the sediment nanogoethite must be significantly smaller than our smallest synthetic reference goethite $\left(211 \mathrm{~m}^{2} / \mathrm{g}, 6.6\right.$ $\mathrm{nm}$, Table DR2 [see footnote 1]; see goethite particle size discussion).

Figure 3A shows the most probable hyperfine field, $H_{\text {peak }}$, of the HFD as a function of the average quadrupole shift parameter, $\langle\boldsymbol{\varepsilon}\rangle$. This plot allows the small-particle hematites to be eliminated as potential candidates, because they have large $H_{\text {peak }}$ values characteristic only of hematites. Bulk hematite has a similar large $H_{\text {peak }}$ value and a positive $<\boldsymbol{\varepsilon}>$ because of the Morin transition. The spread of values for the ferrihydrites is as large as can be expected to occur in nature (Murad and Johnston, 1987; Rancourt et al., 2001). The disordered structures of ferrihydrites lead to near-zero values of $\langle\boldsymbol{\varepsilon}\rangle$. The sediment samples cluster around the reference goethites but exhibit a large spread in $\langle\boldsymbol{\varepsilon}\rangle$ values. Figure 3B shows $<\boldsymbol{\varepsilon}>$ vs. $\sigma_{\mathrm{HFD}}$. The large values of $\sigma_{\mathrm{HFD}}$ of the sediment sample sextets imply that the sextets cannot be attributed to Fh-like materials, and the $\langle\boldsymbol{\varepsilon}\rangle$ values suggest that they are due to goethite. The reference synthetic nanogoethite $\langle\boldsymbol{\varepsilon}>$ values extend toward the sediment points in the order of decreasing particle size. The sediment samples probably contain a large range of goethite particle sizes, always including smaller values than those of the reference goethites, such that $\sigma_{\mathrm{HFD}}$ exhibits a gap between the smallest observed sediment values and those of the reference materials. This finding is confirmed by the spectral shapes, which often contain coexisting sharp and broad sextet components, and by Figure $3 \mathrm{C}$, in which a nanogoethite particle-size continuum clearly emerges in terms of an inverse correlation between $\langle H\rangle$ and $\sigma_{\mathrm{HFD}}$. Smaller particles have broader sextet lines and thus larger values of $\sigma_{\mathrm{HFD}}$ as well as lower $\langle H\rangle$ values compared to larger particles. We conclude that the predominant reactive iron oxyhydroxide in marine and lacustrine sediments must be nanogoethite, on the basis of this continuum of particle sizes and other crystal-chemical features (OH-groupFe-vacancy complexes, cation substitutions, particle coagulation vs. dilution by nonmagnetic matrix material) that also affect the line shapes (Murad and Johnston, 1987; Friedl and
Schwertmann, 1996; Rancourt, 2001). The $\langle\boldsymbol{\varepsilon}>$ values for the oxidized sapropel samples are systematically larger than those of the other sediment samples (Fig. 3B). This result may be due to an admixture of ferrihydrite. The less common magnetite, maghemite, lepidocrocite, and akaganeite oxyhydroxides are eliminated on the basis of their hyperfine parameters (Murad and Johnston, 1987).

\section{GOETHITE PARTICLE SIZE}

Nanogoethite particle sizes were estimated as follows. Synthetic nanogoethite reference materials have measured gas-adsorption specific surface areas that are consistent with XRD line-width particle sizes, extracted from Williamson-Hall plots. These samples are superparamagnetic at RT for sizes (mean diameters) $10.4 \mathrm{~nm}$ and smaller and hyperfine split for sizes $14.4 \mathrm{~nm}$ and larger, suggesting that all our natural diagenetic nanogoethites are smaller than $\sim 12 \mathrm{~nm}$. In addition, the reference nanogoethites have RT average hyperfine field reductions of $\sim 10 \%$, relative to the bulk goethite RT value. This reduction is comparable to that observed in our sediment samples $(\sim 5 \%)$ at LHT, implying a superparamagnetic barrier energy ratio of $4.2 \mathrm{~K} / 295 \mathrm{~K}$ and a corresponding mean sediment nanogoethite size of $\sim 5 \mathrm{~nm}$. These sizes are comparable to the values $1-3 \mathrm{~nm}$ for natural and synthetic twoline ferrihydrites.

\section{DISCUSSION}

The least stable and most reactive iron oxyhydroxide is ferrihydrite, and it is expected to be the first precipitate formed under oxidative and hydrolyzing conditions, in both the water column and in sediments (Schneider, 1988). Ferrihydrite occurs in large amounts in settings of rapid oxidative precipitation, such as at hydrothermal vents and at Fe-rich groundwater outflows. However, it now appears that the main diagenetic reactive precipitate in aquatic sediments is goethite. This development is an apparent contradiction because there is a consensus (Schwertmann and $\mathrm{Mu}$ rad, 1983; Cornell and Schwertmann, 1996) that goethite cannot form directly from ferrihydrite, as can hematite, but must instead directly precipitate from solution, a recent contrary suggestion (Banfield et al., 2000) notwithstanding. This statement would be particularly true in natural settings in which coprecipitation and surface complexation with organic matter, silicate, arsenate, and phosphate would prevent ferrihydrite dissolution (Cornell and Schwertmann, 1996). It therefore appears that diagenetic Fe cycling near the oxic-anoxic boundaries of lake and marine sediments occurs under conditions that directly lead to goethite precipitation, with growth poisoning from coprecipitation to produce nanoscale crystallites. In hindsight, this effect 
is consistent with laboratory studies that show goethite as the predominant synthesis product under various conditions of slow hydrolysis: (1) if $\mathrm{pH}$ is increased slowly or the solution is simply aged, without exceeding critical $\mathrm{pH}$ and $\mathrm{Fe}$ concentration values for ferrihydrite precipitation; (2) starting from $\mathrm{Fe}^{2+}$ if oxygen is admitted slowly; (3) under conditions in which the $\mathrm{Fe}^{3+}$ is supplied by the slow dissolution of ferrihydrite; or (4) by the slow reconstructive oxidation of ferrous double-layer hydroxides (green rust) (Schwertmann et al., 1999; Murphy et al., 1975; Domingo et al., 1993; Schwertmann and Fitzpatrick, 1992).

Because coprecipitation with and surface complexation on the specific reactive iron oxyhydroxide compound present play dominant roles in the cycling and bioavailabilities of both trace metals and key nutrients, as much laboratory attention as has been given to ferrihydrite (Dzombak and Morel, 1990) will need to be directed to nanogoethites. One might expect little difference between nanogoethite and ferrihydrite, because the surface area of iron oxyhydroxide has been reported to control the rate of microbial $\mathrm{Fe}$ reduction (Roden and Zachara, 1996). However, when Fe-reducing bacteria were grown in a minimal-growth medium, instead of in nutrient-rich broth that poorly mimics the bacteria's natural environment, the bacteria were not able to reduce nanogoethite, in contrast to ferrihydrite (Glasauer et al., 2003). The predominance of nanogoethite in aquatic sediments changes our perspective in microbiological studies, such as in the fields of microbe-mineral interactions (Newman and Kolter, 2000; Lower et al., 2001; Childers et al., 2002) and of primary productivity, as resuspended sedimentary iron oxyhydroxides are an important source of Fe and P (Johnson et al., 1999; Berner and Rao, 1994).

\section{ACKNOWLEDGMENTS}

We thank R.K. Kukkadapu and E.E. Roden for the reference goethite samples and the specific surface area values, T. Behrends and S. Bonneville for the nanohematite and six-line ferrihydrite samples, P.-J. Thibault for the two-line ferrihydrites, E. Epping for the Iberian Margin sediments, T. Murphy for the Lake Biwa samples, and D. Kleeza, K. Telmer, and S. Alpay for the boreal forest lake samples (Geological Survey of Canada-MITE, phases I and II). We acknowledge financial assistance from the Natural Sciences and Engineering Research Council of Canada, the European Union Marine Science and Technology Programme, the Royal Netherlands Academy of Arts and Sciences, and the Belgian Federal Office for Scientific, Technical and Cultural Affairs (contract EV/11/20B).

\section{REFERENCES CITED}

Banfield, J., Welch, S.A., Zhang, H., Thomson Ebert, T., and Penn, R.L., 2000, Aggregation-based crystal growth and microstructure development in natural iron oxyhydroxide biomineralization products: Science, v. 289, p. 751-754.

Belzile, N., and Tessier, A., 1990, Interactions be- tween arsenic and iron oxyhydroxides in lacustrine sediments: Geochimica et Cosmochimica Acta, v. 54, p. 103-109.

Berner, R.A., 1973, Phosphate removal from seawater by adsorption on volcanogenic ferric oxides: Earth and Planetary Science Letters, v. 18 , p. $77-86$.

Berner, R.A., and Rao, J.L., 1994, Phosphorus in sediments of the Amazon River and estuaryImplications for the global flux of phosphorus to the sea: Geochimica et Cosmochimica Acta, v. 58, p. 2333-2339.

Childers, S.E., Ciufo, S., and Lovley, D.R., 2002, Geobacter metallireducens accesses insoluble $\mathrm{Fe}(\mathrm{III})$ oxide by chemotaxis: Nature, v. 416, p. 767-769.

Cornell, R.M., and Schwertmann, U., 1996, The iron oxides-Structure, properties, reactions, occurrence and uses: Weinheim, Germany, VCH Publishing Group, 573 p.

Dang, M.-Z., Rancourt, D.G., Dutrizac, J.E., Lamarche, G., and Provencher, R., 1998, Interplay of surface conditions, particle size, stoichiometry, cell parameters, and magnetism in synthetic hematite-like materials: Hyperfine Interactions, v. 117, p. 271-319.

Domingo, C., Rodriguez-Clemente, R., and Blesa, M.A., 1993, Kinetics of oxidative precipitation of iron oxide particles: Colloids and surfaces A: Physicochemical and Engineering Aspects, v. 79, p. 177-189.

Drodt, M., Trautwein, A.X., König, I., Suess, E., and Bender Koch, C., 1997, Mössbauer spectroscopic studies on the iron forms of deepsea sediments: Physics and Chemistry of Minerals, v. 24, p. 281-293.

Dzombak, D.A., and Morel, F.M.M., 1990, Surface complexation modeling: Hydrous ferric oxide: New York, Wiley, 393 p.

Friedl, J., and Schwertmann, U., 1996, Aluminum influence on iron oxides: XVIII. The effect of Al substitution and crystal size on magnetic hyperfine fields of natural goethites: Clay Minerals, v. 31, p. 455-464

Froelich, P.N., Klinkhammer, G.P., Bender, M.L., Luedtke, N.A., Heath, G.R., Cullen, D., Dauphin, P., Hammond, D., Hartman, B., and Maynard, V., 1979, Early oxidation of organic matter in pelagic sediments of the eastern equatorial Atlantic: Suboxic diagenesis: Geochimica et Cosmochimica Acta, v. 43, p. 1075-1090.

Glasauer, S., Weidler, P.G., Langley, S., and Beveridge, T.J., 2003, Controls on Fe reduction and mineral formation by a subsurface bacterium: Geochimica et Cosmochimica Acta, v. 67, p. $1277-1288$.

Johnson, K.S., Chavez, F.P., and Friederich, G.E., 1999, Continental-shelf sediment as a primary source of iron for coastal phytoplankton: Nature, v. 398, p. 697-700.

Kliza, D.A., and Telmer, K., 2001, GSC-MITE phase 1: Lake sediment studies in the vicinity of the Horne smelter in Rouyn-Noranda, Quebec: Ottawa, Geological Survey of Canada (electronic resource, open-file CD).

Lagarec, K., and Rancourt, D.G., 1997, Extended Voigt-based analytical lineshape method for determining $N$-dimensional correlated hyperfine parameter distributions in Mössbauer spectroscopy: Nuclear Instruments and Methods in Physics Research, Section B, v. 129, p. 266-280.

Lovley, D.R., and Phillips, E.J.P., 1988, Novel mode of microbial energy metabolism: Organic carbon oxidation coupled to dissimilatory reduction of iron and manganese: Applied and Environmental Microbiology, v. 54, p. 1472-1480.
Lower, S.K., Hochella, M.F., Jr., and Beveridge, T.J., 2001, Bacterial recognition of mineral surfaces: Nanoscale interactions between Shewanella and $\alpha$-FeOOH: Science, v. 292, p. 1360-1363.

Murad, E., and Johnston, J.H., 1987, Iron oxides and oxyhydroxides, in Long, G.J., ed., Mössbauer spectroscopy applied to inorganic chemistry, Volume 2: New York, Plenum Publishers, p. 507-582.

Murphy, P.J., Posner, A.M., and Quirk, J.P., 1975 , Chemistry of iron in soils: Ferric hydrolysis products: Australian Journal of Soil Research, v. 13 , p. $189-201$.

Newman, D.K., and Kolter, R., 2000, A role for excreted quinones in extracellular electron transfer: Nature, v. 405, p. 94-97.

Raiswell, R., and Canfield, D.E., 1998, Sources of iron for pyrite formation in marine sediments: American Journal of Science, v. 298, p. 219-245.

Rancourt, D.G., 2001, Magnetism of Earth, planetary, and environmental nanomaterials, in Banfield, J.F., and Navrotsky, A., eds., Nanoparticles and the environment: Reviews in Mineralogy and Geochemistry, v. 44, p. 217-292.

Rancourt, D.G., Fortin, D., Pichler, T., Thibault, P.J., Lamarche, G., Morris, R.V., and Mercier, P.H.J., 2001, Mineralogy of natural As-rich hydrous ferric oxide coprecipitate formed by mixing of hydrothermal fluid and seawater: Implications regarding surface complexation and color banding in ferrihydrite deposits: American Mineralogist, v. 86, p. 834-851.

Roden, E.E., and Zachara, J.M., 1996, Microbial reduction of crystalline iron (III) oxides: Influence of oxide surface area and potential for cell growth: Environmental Science and Technology, v. 30, p. 1618-1628.

Schneider, W., 1988, Iron hydrolysis and the biochemistry of iron-The interplay of hydroxide and biogenic ligands: Chimia, v. 42, p. 9-20.

Schwertmann, U., and Fitzpatrick, R.W., 1992, Iron minerals in surface environments, in Skinner, H.C.W., and Fitzpatrick, R.W., eds., Biomineralization: Processes of iron and manganese: Cremlingen, Germany, Catena Verlag, p. 7-30.

Schwertmann, U., and Murad, E., 1983, Effect of $\mathrm{pH}$ on the formation of goethite and hematite from ferrihydrite: Clays and Clay Minerals, v. 31 , p. $277-284$.

Schwertmann, U., Friedl, J., and Stanjek, H., 1999 From $\mathrm{Fe}(\mathrm{III})$ ions to ferrihydrite and then to hematite: Journal of Colloids and Interface Science, v. 209, p. 215-223.

Slomp, C.P., Thomson, J., and de Lange, G.J., 2002, Enhanced regeneration of phosphorus during formation of the most recent eastern Mediterranean sapropel (S1): Geochimica et Cosmochimica Acta, v. 66, p. 1171-1184.

Thamdrup, B., 2000, Bacterial manganese and iron reduction in aquatic sediments: Advances in Microbial Ecology, v. 16, p. 41-84.

Thibault, P.-J., 2002, Caractérization de la ferrihydrite authigénique synthétisée sous différentes conditions et en présence ou absence de bactéries [M.S. thesis]: Ottawa, Ontario, University of Ottawa, $197 \mathrm{p}$.

van der Zee, C., Slomp, C.P., and van Raaphorst, W., 2002, Authigenic P formation and reactive $\mathrm{P}$ burial in sediments of the Nazaré Canyon on the Iberian margin (northeast Atlantic): Marine Geology, v. 185, p. 381-394.

Manuscript received 10 June 2003

Revised manuscript received 18 July 2003

Manuscript accepted 22 July 2003

Printed in USA 